International Journal of Health Sciences
Available online at www.sciencescholar.us
Vol. 5 No. 3, December 2021, pages: 550-564
e-ISSN: 2550-696X, p-ISSN: 2550-6978
https://doi.org/10.53730/ijhs.v5n3.2381

\title{
Early Postoperative Complications in Patients with Acute Myocardial Infarction During Emergency Coronary Bypassing
}

\author{
Borys Todurov a, Alexander Bitsadze ${ }^{b}$, Dina Shorikova ${ }^{c}$
}

Manuscript submitted: 29 July 2021, Manuscript revised: 10 October 2021, Accepted for publication: 18 November 2021

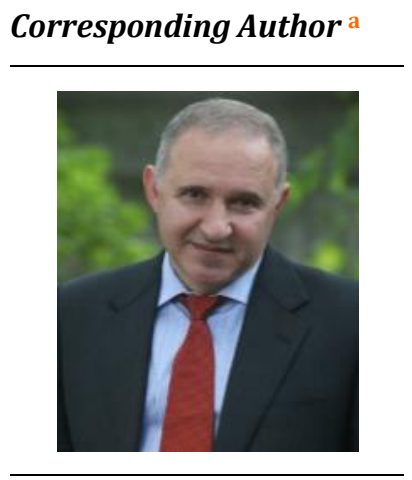

Keywords

mortality;

myocardial infarction;

NSTEMI;

patients;

revascularization;

STEMI;

\begin{abstract}
The article aims to determine the factors of early mortality in emergency coronary artery bypass grafting. Research methods. The research were included 129 patients who were hospitalized in Kyiv "Heart Center" in 20112015, 100 - with ST-elevated myocardial infarction, 29 - with non- ST-elevated myocardial infarction (NSTEMI). Research results. In STEMI patients vs. NSTEMI type was a higher risk of acute heart failure $(\mathrm{p}<0.05)$ followed by intraaortic balloon pulsation $(p<0.05)$ and inotropic support $(p<0.05)$. In the STEMI group acute kidney injury was confirmed by higher indexes of absolute and relative risks $(p<0.05)$. All cases of the transient atrioventricular block were registered in patients with STEMI $(p<0.05)$. However, it was established that the likelihood of supraventricular arrhythmia and encephalopathy in the NSTEMI group was reliably higher $(\mathrm{p}<0.05)$. The level of early postoperative mortality $(12.4 \%)$ proved the probable risk $(\mathrm{p}<0.05)$ in STEMI (log-rank $-2,74$; $\mathrm{p}=0,006)$. Mortality was associated with acute heart failure $(56,2 \%)$, cardiogenic shock (31,3\%), acute mitral regurgitation $(12.5 \%)$. Emergency surgical revascularization in acute MI is an effective method of treatment and can be used taking into account clinical, hemodynamical, and coronary features of myocardial damage.
\end{abstract}

International Journal of Health Sciences (C) 2021. This is an open access article under the CC BY-NC-ND license (https://creativecommons.org/licenses/by-nc-nd/4.0/).

\section{Contents}

Abstract

1 Introduction...

2 Materials and Methods.

3 Results and Discussions

4 Conclusion

\footnotetext{
a Heart institute of $\mathrm{MOH}$ of Ukraine, Kyiv, Ukraine

${ }^{\text {b }}$ Heart institute of MOH of Ukraine, Kyiv, Ukraine

c Bukovinian State Medical University, Chernivtsi, Ukraine
} 


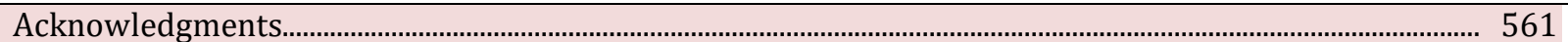

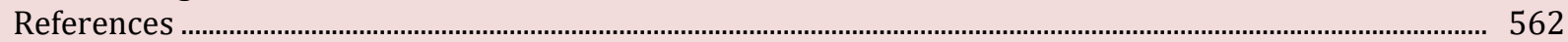

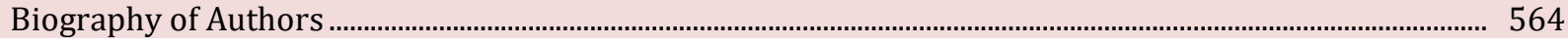

\section{Introduction}

Coronary heart disease is the most common cause of death all over the world. Acute myocardial infarction (AMI) is the most severe complication of coronary heart disease, resulting in acute or progressive heart failure and severe arrhythmias. The most common and immediate cause of death in patients with AMI is ventricular fibrillation (Piccard et al., 2020; Todurov et al., 2021). Despite the results of clinical trials in the field of pharmacology and interventional treatment of patients with AMI, morbidity, and mortality in this form of coronary heart disease are enough high (Seese et al., 2020). Undoubtedly, an invasive strategy of treatment in acute myocardial infarction is more effective than a non-invasive one. As a result, coronary angiography is performed in a significant number of patients with AMI, and, accordingly, the proportion of patients with contraindications for stenting is increased at the last time (Rudenko et al., 2017).

It is set (Nichita-Brendea et al., 2021; Galasso et al., 2021), that myocardial revascularization is the method of choice in acute myocardial infarction. Decisions about PCI or CABG should be based on the risk of appropriate methods, including the risk of death during the procedure and quality of life (Ozawa et al., 2021).

Due to guidelines, methods of surgical revascularization include classic coronary artery bypass grafting and a combination of autogenous shunts with mammaro-coronary anastomosis (Banchs \& Trope, 2004). Today, stenting remains the main method of percutaneous coronary intervention (PCI), but in some cases, "pure" balloon angioplasty can also be used. Therefore, in high-risk patients, the interventional strategy should be performed as early as possible (Isogai et al., 2021), as confirmed in the multicenter studies FRISC II - ICTUS - RITA-3 (Collet et al., 2021). That is, myocardial revascularization in patients with AMI is the method of choice. At the same time, the development of criteria that can influence the decision on the choice of percutaneous coronary intervention (PCI) or coronary artery bypass grafting (CABG) is a topical issue. In recent years, optimization of perioperative management of patients, including myocardial protection, has helped to improve the treatment of emergency surgical revascularization in patients with cardiogenic shock (Nichita-Brendea et al., 2021; Kolesnykov et al., 2019). That is, today emergency coronary artery bypass grafting is no longer considered an intervention of despair. Thus, it is important to study the results of emergency surgical myocardial revascularization in patients with AMI, which were previously considered incurable, or in cases where interventional cardiology is ineffective (Sims et al., 2021).

According to some studies, the clinical strategy should be based on the risk-benefit of appropriate methods, including the risk of death during the procedure, remote myocardial infarction, and stroke compared with improved quality of life, the term without infarction or revascularization. However, in our country, relevant studies have not been conducted (Kosyakovsky et al., 2021).

Also, despite the results of interventional cardiology, the indications for coronary artery bypass grafting in acute myocardial infarction, according to the recommendations, are quite limited (Reeder, 1995). The longterm prognosis for primary PCI and CABG is similar, but the average length of hospital stay for PCI is shorter. In addition, a large number of modern clinics do not have the opportunity to accept a patient urgently for surgery in all clinical cases (Mahendiran et al., 2020). Therefore, it is necessary to propose a strong criterion for the selection of patients with acute myocardial infarction and cardiogenic shock within 12 hours after starting emergency surgical revascularization (Tsai et al., 2010). Mammaro-coronary anastomosis and complete arterial revascularization using two mammaro-coronary anastomoses could be appropriate, but the prognostic value of each of these methods requires further investigation (Matsumura-Nakano et al., 2019; Wang et al., 2021).

A meta-analysis of seven randomized trials, which compared routine angiography with subsequent revascularization and selective invasive strategy, showed a reduction in total mortality and MI after choosing an "early invasive strategy" (BP - 0.82; 95.0\% CI 0.72- $0.93, \mathrm{p}=0.001$ ). The routine revascularization strategy was associated with the risk of early death and MI during initial hospitalization, but in 4 of the 7 studies included in this meta-analysis, the use of IIb/IIIa glycoprotein receptor antagonists was rare. Another metaanalysis of $7 \mathrm{RD}$ with additional treatment, included IIb/IIIa glycoprotein receptor antagonists, showed a

Todurov, B., Bitsadze, A., \& Shorikova, D. (2021). Early postoperative complications in patients with acute myocardial infarction during emergency coronary bypassing. International Journal of Health Sciences, 5(3), 550564. https://doi.org/10.53730/ijhs.v5n3.2381 
significant reduction of mortality risk in all causes (BP $0.75,95.0 \%$ CI $0.63-0.90, \mathrm{p}<0.001$ ) and MI (BP - 0.83, $95,0 \% \mathrm{CI} 0.72-0.96, \mathrm{p}=0.012$ ) with an early invasive strategy compared with a conservative approach in the first two years without death and MI in the first month (Lim et al., 2021). To date, many models have been developed for risk stratification that is important in decision making, taking into account the anatomical complexity of the process and clinical risk (Deutsch et al., 2021). In particular, the EuroSCORE scale calculates the risk of surgical death. However, according to researchers, it is based on outdated data and overestimates the risk of death (Pidgajna et al., 2016). EuroSCORE includes not so much a comprehensive assessment of the severity of the patient's condition taking into account the combined pathology, as individual risk factors with proven statistical significance in the development of a prognostic model of lethal outcome in cardiac surgery in a large sample, although the selection criteria for patients included in EuroSCORE limited (Shoji et al., 2021; Ayuningsih et al., 2021).

A later meta-analysis, which is based on a study of individual patients from three studies comparing routine invasive and selective invasive approaches, showed lower mortality and MI during the 5 -year followup (BP 0.81, 95.0 CI 0.71-0.93, p = 0.002), with the most significant difference in high-risk patients. Age, diabetes, history of MI, ST depression, hypertension, body mass index ( $<25$ or $>35 \mathrm{~kg} / \mathrm{m} \mathrm{2}$ ), and treatment strategy were independent predictors of death and MI during follow-up (Dudek et al., 2018; Yepanchintseva et al., 2020).

All results confirmed the routine invasive strategy but emphasized the importance of risk stratification in the decision-making process (Mahardika et al., 2021; Arimbawa et al., 2021). However, despite the success of interventional cardiology, indications for coronary artery bypass grafting in acute myocardial infarction, according to the recommendations, are quite limited (Thiele et al., 2021; Oliveira et al., 2021).

The long-term prognosis for primary PCI and external CABG is similar, but the average length of hospital stay for PCI is shorter. In addition, a large number of modern clinics do not always have the opportunity to accept a patient urgently for surgery (Fan et al., 2021; Kosyakovsky et al., 2019). Therefore, it is necessary to develop simple clear criteria for selecting patients with acute myocardial infarction for emergency surgical revascularization.

Thus, early postoperative complications are an actual problem of cardiac surgery in patients with acute myocardial infarction after emergency surgical revascularization. This work aims to conduct a prospective analysis of the immediate clinical results of the early postoperative period, to evaluate the factors of early mortality in emergency coronary bypass grafting.

\section{Materials and Methods}

\section{Material of investigation}

The work was performed in the departments of endovascular surgery and angiography, clinical diagnostic department, radiological diagnostics department, clinical diagnostic laboratory of the Kyiv City Heart Center "Heart Institute of the Ministry of Health of Ukraine" (Kyiv). The set of clinical materials was carried out during 2011-2015. The research was based on the observation of 129 patients with acute myocardial infarction (AMI). Of these, 100 patients were diagnosed with acute ST-segment elevation myocardial infarction (STEMI), and 29 were diagnosed as acute ST-segment elevation myocardial infarction with STclinical elevation). In all patients, the time from the onset of clinical symptoms was less than 12 hours (Zitelny et al., 2020). The ratio of men and women in the work was $87(67,4 \%)$ to $42(32,6 \%)$. The age of patients ranged from 38,0 to 78,0 years, with an average of $62,0 \pm 12,5$. Criteria for inclusion of patients in the study were: 1) the presence of acute myocardial infarction with an elevation of the ST segment (STEMI); 2) acute myocardial infarction without ST-segment elevation (NSTEMI); 3) carrying out coronary ventriculography.

According to coronary angiography, in 129 patients included in the study, in general, 370 affected vessels were detected - an average of 2,87 per patient. The one-vascular lesion was found in 2 cases $(1,6 \%)$, twovascular - in 13 cases $(10,1 \%)$, with the vast majority of patients with three-vascular lesion - 114 people. $(88,3 \%)$. At the same time, the lesion of the trunk of the left coronary artery was found in 89 cases $(69,0 \%)$. Revascularization in all patients was performed up to 12,0 hours after the onset of myocardial infarction. Coronary artery bypass grafting was performed using a non-cardioplegic technique with intermittent aortic 
compression and moderate hypothermia $\left(28,5 \pm 0,5^{\circ} \mathrm{C}\right)$. Each patient was fitted with 2,0 to 3,0 shunts. The average number of imposed shunts per patient was $2,70 \pm 0,4$. The average duration of artificial circulation was $61,0 \pm 2,60$ minutes.

The hospital observation period was 14,0-20,0 days, on average $16,0 \pm 2,80$ days after emergency surgical revascularization. During this period, the frequency of intermediate and endpoints was assessed: the need for inotropic support for more than 48 hours, the necessity for intra-aortic balloon counterpulsation (IABP), kidney injury and respiratory failure, the need for rethoracotomy, the episodes of complete atrioventricular block, the occurrence of encephalopathy, nosocomial mortality, and supraventricular tachycardia.

\section{Methods of investigation}

The following research methods were used: clinical, laboratory (blood biomarkers levels (C- and T- troponin, myoglobin, MB-fraction of creatine phosphokinase)), electrocardiography (ECG in 12 standard leads), advanced electrocardiotopography (ECG in 60 leads), 24-hour (by Holter) ECG monitoring, 3Dechocardiography and Doppler echocardiography, coronary angiography (CAG), shuntgraphy.

Diagnostic and control CAG, coronary ventriculography (CVG), and coronary shuntography (CSHG) were performed on an angiographic device AXIOM Artis FA by "Siemens" (Germany), equipped with an electrooptical transducer with image registration on a matrix 512 per inch in the international medical format DICOM. Direct measurement of blood pressure and ECG monitoring is performed using the AXIOM Sensis Information System, which was part of the angiographic complex. The evaluation of the results of coronary angiography and coronary artery bypass grafting was performed quantitatively with the help of angiographic programs specially integrated into the computer system. Calculations were performed in the end-diastolic phase (in the absence of overlapping images of the branches of coronary arteries) in orthogonal projection. All stenotic lesions of the coronary arteries and shunts were analyzed for their radiographic morphological features according to the ACC/AHA classification.

\section{Statistical procedures}

The obtained qualitative and quantitative clinical and instrumental data were entered according to the protocol of the investigation into a computer database. Statistical calculations of the research data were performed using the program modules of "Statistica 7.0" (Statsoft, USA).

The biometric analysis of selected data used the following methods and tools of mathematical statistics: Kolmogorov-Smirnov criterion with Lilliefors correction and Shapiro-Wilk criterion; to compare quantitative values U Wilcoxon homogeneity criterion and Mann-Whitney test was used. For qualitative features, the $\chi^{2}$ criterion with the Yates correction, Fisher's exact F-test, were used. Comparison of quantitative values in several unrelated groups was performed by analysis of variance (ANOVA). The analysis of the probability of outcomes in the investigation was performed by the Kaplan-Meier method. Quantitative data are presented as $\mathrm{M} \pm \mathrm{m}$ (where $\mathrm{M}$ is Mean, and $\mathrm{m}$ is the standard deviation). At $\mathrm{p}<0.05$ the results were considered statistically significant.

\section{Results and Discussions}

Some parameters which are included in the EuroSCORE II scale, such as male sex (absolute risk - 78,0 \%, additive risk $-47,0 \%$, relative risk - 2,51[1,45-4,37], odds ratio - 3,55[3,15-19,8]), previous chronic heart failure functional classes III-IV (absolute risk - 87,0 \%, additive risk - 47,0 \%, relative risk - 1,33[1,0-1,75], odds ratio - 3,52[1,35-9,23]), left ventricular ejection fraction less than 30,0\% (absolute risk - 40,0\%, relative risk - 1,96[1,26-3,05], odds ratio - 6,04[2,48-14,8]), pulmonary hypertension (absolute risk - 99,0\%, additive risk $-61,0 \%$, relative risk $-2,61[1,64-4,16]$, odds ratio $-16,2[19,7-133,9]$ ), creatinine rate filtration less than $50 \mathrm{ml} / \mathrm{min} / 1,73 \mathrm{~m}^{2}$ (absolute risk - 53,0 \%, additive risk $-29,0 \%$, relative risk $-2,20[1,12-4,30]$, odds ratio - 3,54[1,39-9,06]) in patients with acute myocardial infarction in preoperative period were clinically significant for severe myocardial damage. At the same time, some risk factors, stratified in the EuroSCORE II, such as age more than 70 years, previous chronic obstructive pulmonary disease, peripheral

Todurov, B., Bitsadze, A., \& Shorikova, D. (2021). Early postoperative complications in patients with acute myocardial infarction during emergency coronary bypassing. International Journal of Health Sciences, 5(3), 550564. https://doi.org/10.53730/ijhs.v5n3.2381 
artery disease, rhythm and conduction disorders were not reliable for severe myocardial damage in preoperative period $(p>0,05)$.

We have researched the additional risk factors, which were not included in the EuroSCORE II scale, but were clinically relevant for severe myocardial damage in the preoperative period. These factors are arterial hypertension (absolute risk - 78,0\%, additive risk - 23,0 \%, relative risk - 1,41[1,0-1,99], odds ratio $2,88[1,21-6,89]$ ) and 3-vascular coronary arteries lesions (absolute risk - 93,0 \%, relative risk increases in 1,28 times). It has been shown that for both groups, STEMI and NSTEMI, the main types of regional contractility were akinetic (62,8 and 58,0 \%), hypokinetic (20,6 and 26,2\%), and dyskinetic $(16,6$ and 3,4 \%, $\mathrm{p}<0,05)$.

It was set the reliable direct correlation between left ventricle ejection fraction and glomerular rate filtration in patients with acute myocardial infarction before emergency revascularization $(r=0,549, p<0,05)$. The results obtained at this stage made it possible to determine the role of clinical and anamnestic factors as predictors of STEMI or NSTEMI formation before emergency coronary artery bypass grafting (McManus et al., 2011; Widana et al., 2021). Inotropic support for more than 48 hours in the postoperative period was used in $79.8 \%$ of patients (103 people). At the same time, the additional risk of this endpoint in patients with STEMI was $85.0 \%$. Indicators of absolute risk (AR,\%), relative risk (RR), and odds ratio (OR) are presented in Table 1.

Table 1

The need for inotropic support in patients with acute infarction in the postoperative period, depending on the type of myocardial injury

\begin{tabular}{lllll}
\hline & AR, \% & ARR & RR & OR \\
\hline STEMI & 99,0 & & 7,18 & 618,75 \\
$\mathrm{n}=100$ & \multirow{2}{*}{85,0} & {$[2,89-17,9]$} & {$[66,4-5813,9]$} \\
NSTEMI n=29 & 14,0 & & $\mathrm{p}<0.01$ & $\mathrm{p}<0.01$ \\
\hline
\end{tabular}

It also confirmed the position that the severity of myocardial damage before surgical revascularization is a factor that complicates the early activation of patients and increases the duration of treatment in the intensive care unit, table. 2 .

Table 2

Peculiarities of the postoperative period in emergency surgical revascularization depending on the type of myocardial injury

\begin{tabular}{|c|c|c|c|}
\hline & STEMI & NSTEMI & $\mathrm{p}$ \\
\hline Duration of inotropic therapy, $\mathrm{h}$. & $68,9 \pm 16,4$ & $52,3 \pm 8,4$ & $<0.05$ \\
\hline Duration of respiratory support, $\mathrm{h}$. & $36,8 \pm 8,2$ & $24,2 \pm 7,8$ & $<0.05$ \\
\hline care unit, h. & $78,7 \pm 13,7$ & $63,8 \pm 9,4$ & $<0.05$ \\
\hline
\end{tabular}

p - reliability of the difference in data between the observation groups.

The need for intra-aortic balloon counterpulsation (IABP) in patients with acute myocardial infarction during surgery occurred in $27,1 \%$ of cases (35 patients out of 129). At the same time, the absolute risk of left ventricular failure followed by IABP procedure in the STEMI group was 32,0\% versus $10,0 \%$ in the NSTEMI group, with a risk reduction of $22,0 \%$ in group 2 . Relative risk indexes were also established $(\mathrm{p}<0.05)$ and odds ratios $(\mathrm{p}<0.05)$ of IABP in patients of the STEMI group, tab. 3.

Table 3

Risk of left ventricular failure during emergency surgical revascularization, depending on the type of myocardial injury

\begin{tabular}{lllll}
\hline & AR, \% & ARR & RR & OR \\
\hline STEMI & 32,0 & & 3,09 & 4,08 \\
$\mathrm{n}=100$ & 22,0 & {$[1,02-9,39]$} & {$[1,15-14,5]$} \\
NSTEMI $n=29$ & 10,0 & & $\mathrm{p}<0.05$ & $\mathrm{p}<0.05$ \\
\hline
\end{tabular}


One of the most important steps in clinical research is the choice of an endpoint that characterizes the disease and objectively evaluates the effect of surgery. In the cumulative analysis of the likelihood of acute left ventricular failure (Kaplan-Meier method), the median of the event was established after 6,69 days, with reliable indicators of the Log-Rank test after 2,73 days $(p=0.006)$, Fig. 1.

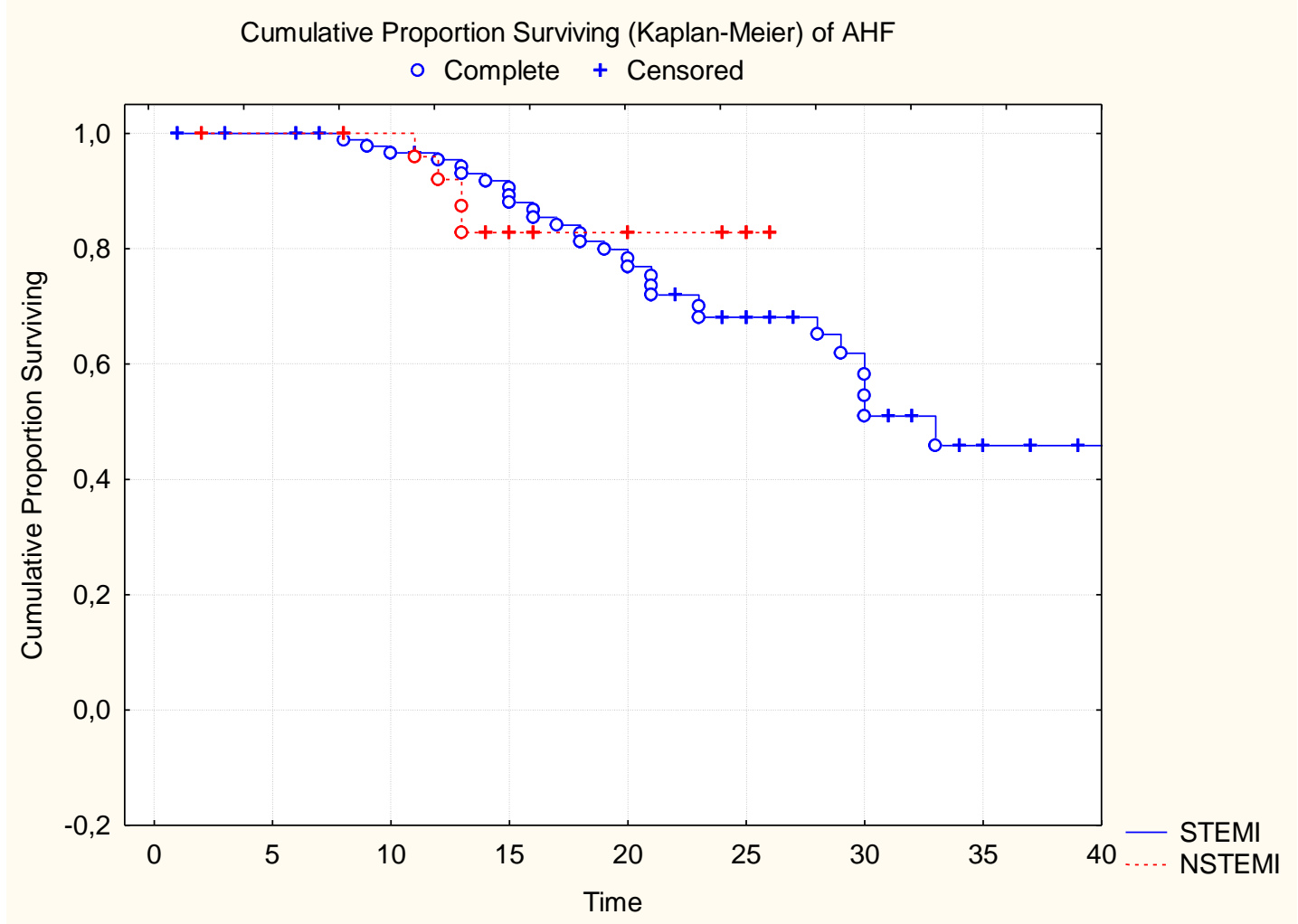

Figure 1. Cumulative analysis of the likelihood of acute left ventricular failure in patients with acute infarction after surgical revascularization

Acute kidney injury after emergency coronary bypass grafting was registered in 5,4\% of cases (7 people) among all examined patients (129 people). All patients with a decrease in glomerular filtration rate below $50.0 \mathrm{ml} / \mathrm{min}$. were assigned to the STEMI group in the preoperative period.

Table 4

The risk of acute kidney injury in the postoperative period depending on the type of myocardial injury

\begin{tabular}{llll}
\hline & AR, $\%$ & RR & OR \\
\hline STEMI & 7,0 & 203,07 & 218,28 \\
$\mathrm{n}=100$ & & {$[6,13-677,3]$} & {$[6,53-734,6]$} \\
NSTEMI & 0,0 & $\mathrm{p}<0.05$ & $\mathrm{p}<0.05$ \\
$\mathrm{n}=29$ & & & \\
\hline
\end{tabular}

The additional risk of acute kidney injury after emergency surgical revascularization corresponded to the absolute risk and severity of myocardial injury $(7.0 \%)$, with significant evidence of the relative risk $(\mathrm{p}<0.05)$ and odds ratio $(\mathrm{p}<0.05)$, table 4 . The frequency of respiratory failure in the early postoperative period was set at $7.0 \%$ ( 9 patients), table 5 .

Todurov, B., Bitsadze, A., \& Shorikova, D. (2021). Early postoperative complications in patients with acute myocardial infarction during emergency coronary bypassing. International Journal of Health Sciences, 5(3), 550- 
Table 5

The risk of respiratory failure in the postoperative period depending on the type of myocardial injury

\begin{tabular}{lllll}
\hline & AR, \% & ARR & RR & OR \\
\hline STEMI & 8,0 & & 2,32 & 2,43 \\
$\mathrm{n}=100$ & \multirow{2}{*}{5,0} & {$[0,30-17,8]$} & {$[0,29-20,4]$} \\
NSTEMI $\mathrm{n}=29$ & 3,0 & & $\mathrm{p}>0.05$ & $\mathrm{p}>0.05$ \\
\hline
\end{tabular}

Prolonged mechanical ventilation occupied the main place in the structure of respiratory complications among the examined patients. At the same time, the absolute risk of respiratory failure after surgical revascularization in patients with acute myocardial infarction on the background of ST-segment elevation was set at $8,0 \%$ versus 3,0\% in the absence of ST-segment elevation and absolute risk reduction was set at 5,0\%.

There were also established significant changes in the relative risk $(\mathrm{p}<0.05)$ and the odds ratio $(\mathrm{p}<0.05)$ of respiratory complications in the presence of acute myocardial injury of the STEMI type, table 5 . At the same time, the absolute risk of rethoracotomy after coronary artery bypass grafting was 3,0\% (STEMI) and 3,4\% (NSTEMI). It was noted that the type of acute myocardial injury was not a determining factor for this complication, and the relative risk and odds ratio were unreliable ( $p>0.05)$, tab. 6.

Table 6

Rethoracotomy in the postoperative period depending on the type of myocardial injury

\begin{tabular}{llll}
\hline & $\mathrm{AR}, \%$ & $\mathrm{RR}$ & $\mathrm{OR}$ \\
\hline STEMI & 3,0 & 0,87 & 0,87 \\
$\mathrm{n}=100$ & & {$[0,09-8,06]$} & {$[0,09-8,67]$} \\
NSTEMI & 3,4 & $\mathrm{p}>0.05$ & $\mathrm{p}>0.05$ \\
$\mathrm{n}=29$ & & & \\
\hline
\end{tabular}

The absolute risk of encephalopathy in patients with NSTEMI is set at 10,3\%, and in the STEMI group - 6,0\%, the relative risk is $0,58[0,15-2,18]$, the odds ratio is $0,55[0,13-2,37]$, tab. 7 .

Table 7

The risk of encephalopathy in the postoperative period depending on the type of myocardial injury

\begin{tabular}{llll}
\hline & $\mathrm{AR}, \%$ & $\mathrm{RR}$ & $\mathrm{OR}$ \\
\hline STEMI & 6,0 & 0,58 & 0,55 \\
$\mathrm{n}=100$ & & {$[0,15-2,18]$} & {$[0,13-2,37]$} \\
NSTEMI & 10,3 & $\mathrm{p}<0.05$ & $\mathrm{p}<0.05$ \\
$\mathrm{n}=29$ & & &
\end{tabular}

The absolute risk of transient atrioventricular (AV) block in patients with STEMI type of myocardial injury was $4,0 \%$ versus $0,0 \%$ in patients with NSTEMI type of acute infarction, with a significant relative risk $(\mathrm{p}<0.05)$ and odds ratio $(\mathrm{p}<0.05)$, tab. 8 .

Table 8

The risk of transient AV block in the early postoperative period depending on the type of myocardial injury

\begin{tabular}{lllll}
\hline & AR, \% & ARR & RR & OR \\
\hline STEMI & 4,0 & & 116,0 & 120,8 \\
$\mathrm{n}=100$ & 4,0 & {$[3,46-391,0]$} & {$[3,58-410,8]$} \\
NSTEMI $\mathrm{n}=29$ & 0,0 & & $\mathrm{p}<0.05$ & $\mathrm{p}<0.05$ \\
\hline
\end{tabular}

The absolute risk of supraventricular tachcardia in the STEMI group was $9,0 \%$, while in NSTEMI patients 21,0 ; relative risk - 0,44 [0,17-1.12], odds ratio - 0,38 [0,12-1,17], table 9. 
Table 9

The risk of supraventricular tachycardia in the early postoperative period depending on the type of myocardial injury

\begin{tabular}{llll}
\hline & $\mathrm{AR}, \%$ & $\mathrm{RR}$ & $\mathrm{OR}$ \\
\hline STEMI & 9,0 & 0,44 & 0,38 \\
$\mathrm{n}=100$ & & {$[0,17-1,12]$} & {$[0,12-1,17]$} \\
NSTEMI & 21,0 & $\mathrm{p}<0.01$ & $\mathrm{p}<0.01$ \\
$\mathrm{n}=29$ & & & \\
\hline
\end{tabular}

Postoperative mortality in patients with acute myocardial infarction was $12.4 \%$ (16 clinical cases), Figure 2. At the same time, according to the cumulative analysis of Kaplan-Meier survival, all cases of postoperative mortality were registered in patients who had myocardial infarction with ST-segment elevation with significant Log-rank test $(2,74 ; p=0,006)$, Figure 3 .

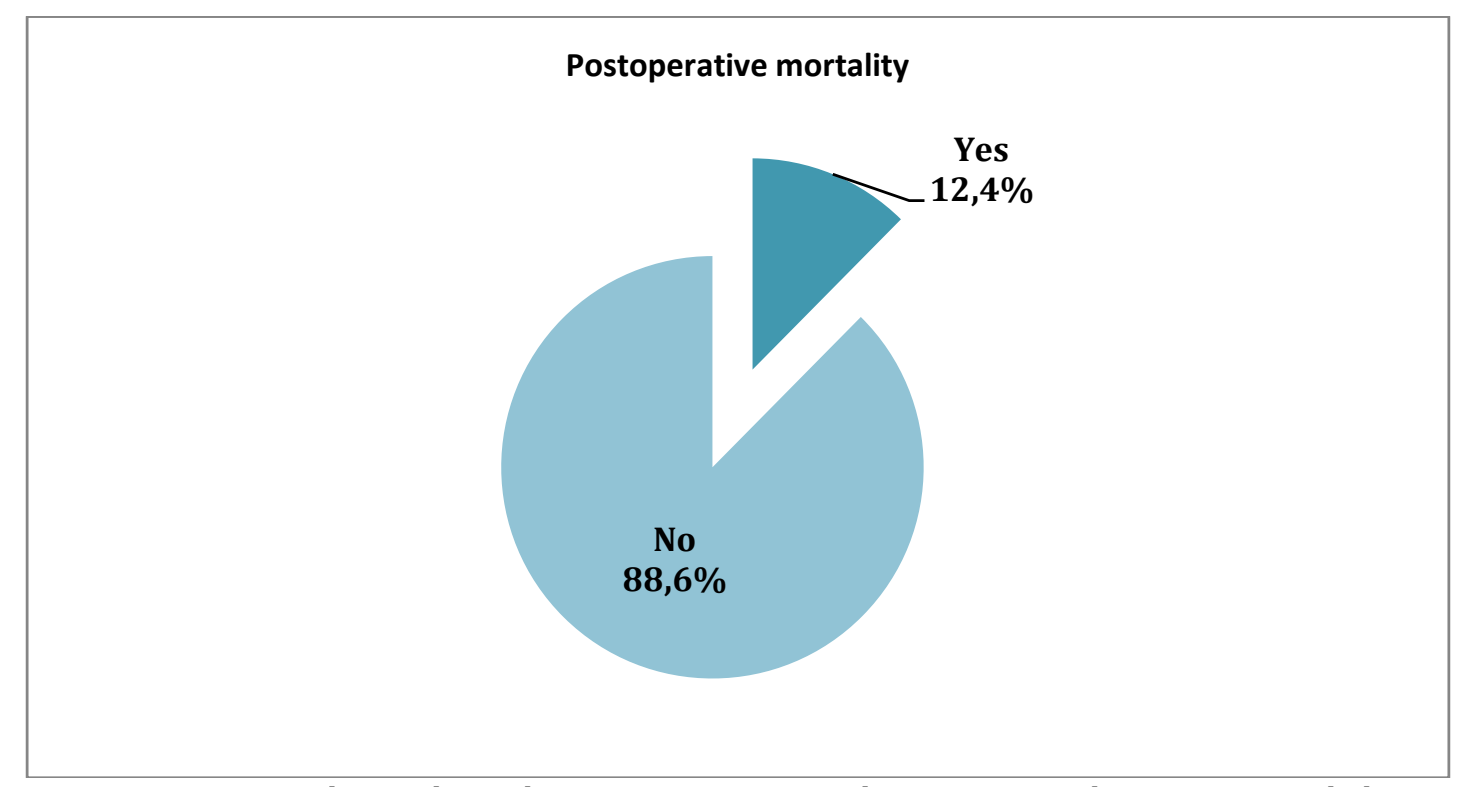

Figure 2. Mortality in the early postoperative period in patients with acute myocardial infarction after surgical revascularization

Todurov, B., Bitsadze, A., \& Shorikova, D. (2021). Early postoperative complications in patients with acute myocardial infarction during emergency coronary bypassing. International Journal of Health Sciences, 5(3), 550564. https://doi.org/10.53730/ijhs.v5n3.2381 


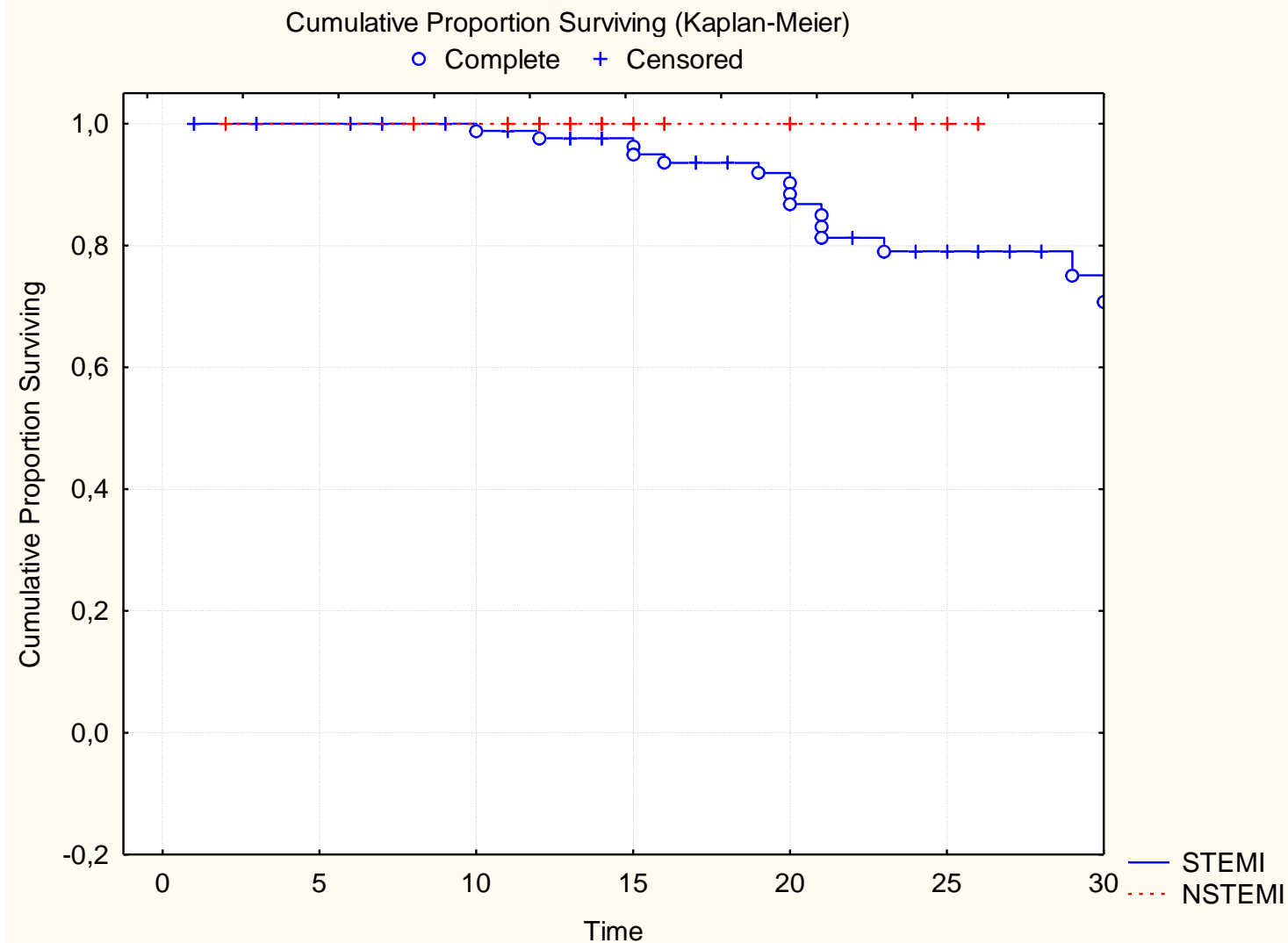

Figure 3. Cumulative analysis of survival according to Kaplan-Meier in patients with acute myocardial infarction in the early postoperative period

The absolute risk of mortality in the STEMI group was $16,0 \%$ with identical ARR, significant relative risk $(\mathrm{p}<0.05)$, and odds ratio $(\mathrm{p}<0.05)$, table. 10 .

Table 10

Absolute and relative risks, the odds ratio of postoperative mortality depending on the type of myocardial injury

\begin{tabular}{lllll}
\hline & AR, \% & ARR & RR & OR \\
\hline STEMI & 16,0 & & 464,16 & 552,38 \\
$\mathrm{n}=100$ & \multirow{2}{*}{16,0} & {$[1,41-536,9]$} & {$[1,67-845,6]$} \\
NSTEMI n=29 & 0,0 & & $\mathrm{p}<0.01$ & $\mathrm{p}<0.01$ \\
\hline
\end{tabular}

The ratio of acute mitral regurgitation (followed by mitral valve replacement) and early postoperative mortality was also reliable: Pearson's $\chi 2-12,76(p=0,003)$, conjugation coefficient $\eta-0,336(p<0,001)$, tab. 11.

Table 11

Acute mitral regurgitation, relative risk and odds ratio of cardiogenic shock in patients with myocardial infarction and ST-segment elevation

\begin{tabular}{lll}
\hline & RR & OR \\
\hline \multirow{2}{*}{ Indexes } & 2,408 & 11,11 \\
& {$[1,853-3,963]$} & {$[2,35-52,59]$} \\
\hline
\end{tabular}


The relative risk and odds ratio of early mortality was reliable $(\mathrm{p}<0.05)$, as evidenced by the confidence interval. So, the study presents the prospective analysis and immediate results of emergency surgical revascularization in acute myocardial infarction, such as clinical outcomes in the postoperative period. To achieve this goal, surrogate points (acute left ventricular failure, kidney, and respiratory failure, retoracotomy, complete AV-blockade, supraventricular arrhythmia, encephalopathy) and end-points (hospital mortality) were identified. The period of observation, which includes the time of admission and emergency revascularization to the time of discharge, was divided into 4 periods - 1 day, 2-5 days, 6-14 days, 15-30 days. However, our study identified high absolute risk and probable relative risk of the need for inotropic support in the postoperative period in the presence of STEMI, as well as the occurrence of left ventricular failure followed by IABP procedure. The risk of left ventricular failure was confirmed by the Kaplan-Meier method by log-rank criterion. Acute kidney injury with decreased glomerular filtration rate has been reported in patients in the STEMI group, with higher absolute and relative risk, and odds ratios. Similar results were obtained in Dieberg et al., who proved that the type of myocardial damage is an important prognostic factor in early postoperative mortality - in patients with viable myocardium who underwent myocardial revascularization. In this case, there were significantly lower rates of serious cardiovascular complications, re-hospitalizations, progression of chronic heart failure, compared with patients who did not perform revascularization of viable myocardium (Collet et al., 2021).

It was proved, that frequent surrogate points in the early postoperative period at patients with STEMI after emergency revascularization were respiratory complications and mechanical ventilation $(7,0 \%)$, intraaortic balloon counterpulsation (27,1\%), prolonged (more than 48 hours) inotropic support (99,0\%), acute kidney failure $(7,0 \%, p<0,05)$, acute respiratory failure $(7,0 \%, p<0,05)$, atrioventricular blockade $(p<0,05)$. The peculiarities of the early postoperative period in patients with NSTEMI were a higher risk of acute encephalopathy $(p<0,05)$ and supraventricular arrhythmia $(20,7 \%, p<0,05)$.

Thus, in our study, the assessment of the hard (inflexible) endpoint (hospital mortality) confirmed the presence of a high absolute risk of mortality in the STEMI group, with probable odds ratio, relative risk, and level of cumulative survival according to the analysis of Kaplan-Meyer. During the 1st day 2 deaths were registered, between $2-5$ days - 8 deaths, for $6-14$ days the mortality rate was $6,0 \%$, the total hospital mortality rate was $16,0 \%$. No episodes of death were reported after the 14th day of hospital stay. Mortality had a close link to acute heart failure, cardiogenic shock, and acute mitral regurgitation. A prospective analysis of mortality by cause was also performed, which, in summary, allows us to determine the important role of the severity of myocardial damage as a prognostic factor during the postoperative period.

A study by Pieri M. et al., which included 7,313 patients with the acute coronary syndrome, showed a significantly higher level of cardiac mortality in the optimal drug therapy group than in patients who underwent surgical myocardial revascularization. That is, the authors insist on the possibility of emergency surgical myocardial revascularization in the presence of acute myocardial infarction, and survival, according to these authors depends on the initial value of ejection fraction of the left ventricle (Mahendiran et al., 2020).

In another study, Koerich C. et al., in evaluating the treatment outcomes of patients with severe coronary artery disease and left ventricular systolic dysfunction who underwent CABG, showed that in patients who were assessed for myocardial viability, the postoperative survival rate was significantly higher compared to with patients in whom only coronary angiograms were analyzed before surgery and amounted to 97,0 and $79,0 \%$, respectively $(\mathrm{p}<0.05)$. The authors also emphasize that in the first hours and days after surgery, in the group with viable myocardium, smaller amounts of catecholamine support were required (Dudek et al., 2018).

The analysis of the direct results of emergency surgical revascularization in patients with acute myocardial infarction revealed that the predominant position in the structure of respiratory complications among the examined patients was prolonged mechanical ventilation $(7,0 \%)$, high absolute $(79.8 \%)$, and probable relative $(\mathrm{p}<0.05)$ risk of the need for inotropic support in the postoperative period, high level $(32,0 \%)$ and probable odds $(\mathrm{p}<0.05)$ of development of left ventricular failure followed by intra-aortic balloon counterpulsation $(27,1 \% ; p<0.05)$, significant relative risk and odds of developing acute kidney injury $(p<0.05)$, transient atrioventricular block $(\mathrm{p}<0.05)$ in the presence of STEMI.

In the work of Rudenko (2017) an analysis of the results of coronary artery bypass grafting of patients treated at the National Institute of Cardiovascular Surgery named after M.M. Amosov in the period from 2009 to 2013 was done. In this study, unfavorable factors of intraoperative and postoperative complications recognized unstable hemodynamics, intraoperative arrhythmias, intraoperative bleeding, and ECG changes

Todurov, B., Bitsadze, A., \& Shorikova, D. (2021). Early postoperative complications in patients with acute myocardial infarction during emergency coronary bypassing. International Journal of Health Sciences, 5(3), 550564. https://doi.org/10.53730/ijhs.v5n3.2381 
during surgery, mortality in isolated coronary artery bypass surgery in 2013 was $0.4 \%$ (Ozawa et al., 2021). In our study, patients with acute myocardial infarction type NSTEMI verified a higher absolute (10,3\%), probable relative risk and chances of acute encephalopathy $(\mathrm{p}<0.05)$, a greater number of clinical cases of supraventricular tachycardia $(20,7 \%, \mathrm{p}<0.05)$.

Estimation of the level of early postoperative mortality $(12,4 \%)$ proved the probable relative risk $(\mathrm{p}<0.05)$ and the odds ratio $(\mathrm{p}<0.05)$ of mortality in the STEMI group, which was confirmed by the analysis of cumulative survival by the Kaplan-Meyer method (criterion) log-rank 2,74; $p=0,006$ ). Mortality in the STEMI group was associated with previously diagnosed acute heart failure $(56,2 \%)$, the onset of cardiogenic shock $(31,3 \%)$, and the development of acute mitral regurgitation $(12,5 \%)$. According to the American Association of Cardiothoracic Surgeons, mortality from coronary artery bypass grafting depends on the surgical technique and is, in the analysis of many studies, $1,4 \%$ without artificial circulation and 2,3\% with artificial circulation in men, $1,7 \%$ and 3,6\% accordingly, in women The authors also indicate that coronary artery bypass graft surgery on a working heart can be a safe method of performing interventions for almost all categories of patients in need of surgical correction of coronary artery disease, and can be used in $97.0 \%$ of cases (Pidgajna et al., 2016).

It has been established, that clinical end-points during long-term observation after emergency coronary artery bypass in patients with acute myocardial infarction are presented by mortality rate $0,9 \%$, recurrence angina with a probability of 3,5\%, shunt thrombosis $(0,9 \%)$, acute cerebrovascular disorders $(0,9 \%)$. It wasn 't noted chronic heart failure progression, re-infarction, re-hospitalization in both groups during longterm observation. And there were no significant differences between STEMI and NSTEMI groups in the incidence and clinical outcomes in long-term observation versus early postoperative period.

Our results differ from those presented by Pidgajna et al. (2016), relative to the prognostic value of acute mitral regurgitation of ischemic origin. All patients underwent coronary artery bypass graft surgery and mitral valve plastic surgery with a ring or sutures. The authors indicate that the course of the early postoperative period was uncomplicated, there were no cases of sudden death (Matsumura-Nakano et al., 2019). Foreign studies also indicate that the addition of mitral valve plastics to coronary artery bypass graft surgery in patients with moderate ischemic mitral regurgitation may improve cardiac function, reverse left ventricular remodeling, and reduce mitral regurgitation.

\section{Conclusion}

In this prospective study, the effectiveness of emergency surgical revascularization in patients with acute myocardial infarction was evaluated, the results of the early postoperative period were analyzed and the factors of early mortality were determined. The analysis of the direct results of emergency surgical revascularization in patients with acute myocardial infarction revealed that the predominant place in the structure of respiratory complications among the examined patients was prolonged mechanical ventilation $(7,0 \%)$, high absolute $(79,8 \%)$, and reliable relative $(\mathrm{p}<0.05)$ risk of the need for inotropic support in the postoperative period, high level $(32,0 \%)$ and odds ratio $(\mathrm{p}<0.05)$ of development of left ventricular failure followed by intra-aortic balloon counterpulsation $(27,1 \%, p<0,05)$, significant relative risk and odds of developing acute kidney injury $(p<0.05)$, and transient atrioventricular block $(p<0.05)$ in the presence of STEMI.

Patients with acute myocardial infarction with NSTEMI type verified higher absolute (10.3\%), probable relative risk and odds of acute encephalopathy $(\mathrm{p}<0.05)$, a higher percentage of clinical cases with supraventricular tachycardia $(20,7 \%, \mathrm{p}<0.05)$. It has been proven that all cases of the transient atrioventricular blockade were registered in patients who had previous acute myocardial infarction with STsegment elevation in the preoperative period, significant odds ratio, absolute and relative risks $(p<0.05)$. It was found that the main structure of respiratory complications among the examined patients was due to prolonged mechanical ventilation, but the difference between the groups in terms of STEMI and NSTEMI odds ratio and relative risk was insignificant $(\mathrm{p}>0.05)$.

Estimation of the level of early postoperative mortality $(12,4 \%)$ showed a significant increase in the probable relative risk $(\mathrm{p}<0.05)$ and odds $(\mathrm{p}<0.05)$ in the STEMI group, which was confirmed by the analysis of cumulative survival by the Kaplan-Meier method (log-rank criterion $-2,74, p=0,006$ ). Mortality in the STEMI 
group was associated with previously diagnosed acute heart failure (56.2\%), the onset of cardiogenic shock $(31.3 \%)$, and the development of acute mitral regurgitation $(12.5 \%)$. In the postoperative period of emergency surgical revascularization during acute infarction, risk factors should be carefully assessed to predict early postoperative mortality - changes in left ventricular systolic dysfunction, the development of kidney injury, the presence of pulmonary hypertension, the onset of the atrioventricular block during the intervention. Prospects for further research are long-term prospective observation, analysis of long-term clinical results of coronary artery bypass grafting in patients with acute myocardial infarction, as well as assessment of risk factors for long-term mortality.

Acknowledgments

We are grateful to two anonymous reviewers for their valuable comments on the earlier version of this paper.

Todurov, B., Bitsadze, A., \& Shorikova, D. (2021). Early postoperative complications in patients with acute myocardial infarction during emergency coronary bypassing. International Journal of Health Sciences, 5(3), 550564. https://doi.org/10.53730/ijhs.v5n3.2381 


\section{References}

Arimbawa, . I. M., Paramita, A. D. P., Nuaba, I. G. A., \& Saputra, H. (2021). Management of hypocalcemia after modified bilateral radical neck dissection followed with total thyroidectomy: a case report. International Journal of Health Sciences, 5(1), 9-19. https://doi.org/10.29332/ijhs.v5n1.654

Ayuningsih, N. N., Suda, I. K., \& Subrata, I. W. (2021). Sewaka dharma hindu nurse toward patients in sanglah general hospital denpasar. International Journal of Health \& Medical Sciences, 4(1), 80-87.

Banchs, F., \& Trope, M. (2004). Revascularization of immature permanent teeth with apical periodontitis: new treatment protocol?. Journal of endodontics, 30(4), 196-200. https://doi.org/10.1097/00004770200404000-00003

Collet, J. P., Thiele, H., Barbato, E., Barthélémy, O., Bauersachs, J., Bhatt, D. L., \& Karia, N. (2021). 2020 ESC Guidelines for the management of acute coronary syndromes in patients presenting without persistent STsegment elevation: the Task Force for the management of acute coronary syndromes in patients presenting without persistent ST-segment elevation of the European Society of Cardiology (ESC). European heart journal, 42(14), 1289-1367.

Deutsch, M. A., Zittermann, A., Renner, A., Schramm, R., Götte, J., Börgermann, J., \& Gummert, J. F. (2021). Riskadjusted analysis of long-term outcomes after on-versus off-pump coronary artery bypass grafting. Interactive CardioVascular and Thoracic Surgery, 33(6), 857-865.

Dudek, D., Ebner, A., Sobczyński, R., Trębacz, J., Vesga, B., Granada, J., \& Żmudka, K. (2018). Efficacy and safety of the HeartMate percutaneous heart pump during high-risk percutaneous coronary intervention (from the SHIELD I trial). The American journal of cardiology, 121(12), 1524-1529. https://doi.org/10.1016/j.amjcard.2018.02.046

Fan, X., Li, M., Cao, J., \& Liang, Z. (2021). Application of thrombolysis in myocardial infarction risk index in the prediction of long-term outcomes for patients with ST-elevation myocardial infarction and multiple vessel disease: A single-center prospective observational cohort study. Experimental and Therapeutic Medicine, 22(6), 1-8.

Galasso, G., De Angelis, E., Silverio, A., Di Maio, M., Cancro, F. P., Esposito, L., ... \& Vecchione, C. (2021). Predictors of Recurrent Ischemic Events in Patients With ST-Segment Elevation Myocardial Infarction. The American Journal of Cardiology, 159, 44-51. https://doi.org/10.1016/j.amjcard.2021.08.019

Isogai, T., Saad, A. M., Kaur, M., Shekhar, S., Gad, M. M., Miyasaka, R. L., ... \& Kapadia, S. R. (2021). Transcatheter Mitral Valve Repair and Mitral Valve Surgery Following Acute Myocardial Infarction (Insights From a Nationwide Cohort Study). American Journal of Cardiology, 152, 174-177.

Kolesnykov, V., Loskutov, O., Druzhyna, O., Maruniak, S., \& Todurov, B. (2019). Features of cerebral blood flow dynamics in patients with arterial hypertension during cardiac surgery. Georgian medical news, (286), 1319.

Kosyakovsky, J., Witthuhn, B. A., Svitak, A. L., Frey, W. H., Hanson, L. R., \& Fine, J. M. (2019). Quantifying Intranasally Administered Deferoxamine in Rat Brain Tissue with Mass Spectrometry. ACS chemical neuroscience, 10(11), 4571-4578.

Kosyakovsky, L. B., Austin, P. C., Ross, H. J., Wang, X., Abdel-Qadir, H., Goodman, S. G., ... \& Lee, D. S. (2021). Early invasive coronary angiography and acute ischaemic heart failure outcomes. European heart journal, 42(36), 3756-3766.

Lim, H., Sukmawati, M., Artana, W. D., Kardana, M., \& Putra, P. J. (2021). Validity of neutrophil lymphocyte count ratio in neonatal sepsis. International Journal of Health Sciences, 5(2), 53-61. https://doi.org/10.29332/ijhs.v5n2.1148

Mahardika, I. M. R., Suyasa, I. G. P. D., Kamaryati, N. P., \& Wulandari, S. K. (2021). Health literacy is strongest determinant on self-monitoring blood glucose (SMBG) type 2 DM patients during COVID-19 pandemic at public health centre in Tabanan Regency. International Journal of Health \& Medical Sciences, 4(3), 288-297.

Mahendiran, T., Nanchen, D., Meier, D., Gencer, B., Klingenberg, R., Räber, L., ... \& Fournier, S. (2020). Optimal Timing of Invasive Coronary Angiography following NSTEMI. Journal of interventional cardiology, 2020.

Matsumura-Nakano, Y., Shiomi, H., Morimoto, T., Furukawa, Y., Nakagawa, Y., Kadota, K., ... \& CREDO-Kyoto PCI/CABG Registry Cohort-2 Investigators. (2019). Surgical ineligibility and long-term outcomes in patients with severe coronary artery disease. Circulation Journal, 83(10), 2061-2069. 
McManus, D. D., Gore, J., Yarzebski, J., Spencer, F., Lessard, D., \& Goldberg, R. J. (2011). Recent trends in the incidence, treatment, and outcomes of patients with STEMI and NSTEMI. The American journal of medicine, 124(1), 40-47. https://doi.org/10.1016/j.amjmed.2010.07.023

Nichita-Brendea, M. T., Popescu, M. I., Popa, V., \& Carmen, P. C. D. (2021). A clinical trial comparing complete revascularization at the time of primary percutaneous coronary intervention versus during the index hospital admission in patients with multi-vessel coronary artery disease and ST-elevation myocardial infarction uncomplicated by cardiogenic shock. Anatolian journal of cardiology, 25(11), 781.

Oliveira, P., Madeira, M., Ranchordas, S., Marques, M., Almeida, M., Sousa-Uva, M., ... \& Neves, J. (2021). Complete surgical revascularization: different definitions, same impact?. Authorea Preprints.

Ozawa, T., Kawasaki, Y., \& Suenaga, E. (2021). Coronary Artery Bypass Grafting and Mitral Annuloplasty in a Patient with Left Ventricular Noncompaction with Low Ejection Fraction: Report of a Case. Kyobu geka. The Japanese Journal of Thoracic Surgery, 74(9), 672-675.

Piccard, M., Roussot, A., Cottenet, J., Cottin, Y., Zeller, M., \& Quantin, C. (2020). Spatial distribution of in-and out-of-hospital mortality one year after acute myocardial infarction in France. American Journal of Preventive Cardiology, 2, 100037. https://doi.org/10.1016/j.ajpc.2020.100037

Pidgajna, L., Mohnatij, S. I., Revenko, K. A., Bablyak, O. D., Rudenko, N. M. (2016). Ishemichna mitral'na nedostatnist', mekhanizmi viniknennya ta ocinka iï hirurgichnoï korekciï. Visnik sercevo-sudinnoï hirurgiï,, $25,25-28$.

Reeder, G. S. (1995). Identification and treatment of complications of myocardial infarction. In Mayo Clinic Proceedings (Vol. 70, No. 9, pp. 880-884). Elsevier. https://doi.org/10.4065/70.9.880

Rudenko A. V., Nastenko E. A., Zhurba O. A., Nosovets E. K., Shardukova Yu. V., Lazoryshynets V. V. (2017). Otsenka faktorov ryska pry operatsyiakh aorto-koronarnoho shuntyrovanyia na rabotaiushchem serdtse. Kybernetyka y vichyslytelnaia tekhnyka. 2(188), 75-87.

Seese, L., Sultan, I., Gleason, T., Wang, Y., Thoma, F., Navid, F., \& Kilic, A. (2020). Outcomes of conventional cardiac surgery in patients with severely reduced ejection fraction in the modern era. The Annals of thoracic surgery, 109(5), 1409-1418. https://doi.org/10.1016/j.athoracsur.2019.08.033

Shoji, K., Yanishi, K., Kawamata, H., Hori, Y., Fujioka, A., Kohno, Y., ... \& Study, A. K. M. C. R. (2021). New risk factors for early-and late-onset cardiac rupture in ST-elevation myocardial infarction patients after primary percutaneous coronary intervention. Journal of Cardiology. https://doi.org/10.1016/j.jjcc.2021.10.006

Sims, D. B., Kim, Y., Kalininskiy, A., Yanamandala, M., Josephs, J., Rivas-Lasarte, M., ... \& Jorde, U. P. (2021). FullTime Cardiac Intensive Care Unit Staffing by Heart Failure Specialists and its Association with Mortality Rates. Journal of Cardiac Failure. https://doi.org/10.1016/j.cardfail.2021.09.013

Thiele, H., de Waha-Thiele, S., Freund, A., Zeymer, U., Desch, S., \& Fitzgerald, S. (2021). Management of cardiogenic shock. Eurointervention: Journal of Europcr in Collaboration with the Working Group on Interventional Cardiology of the European Society of Cardiology, 17(6), 451-465.

Todurov, B., Kharenko, Y., Khartanovich, M., Mokryk, I., \& Zelenchuk, O. (2021). Comparison Of Levels Of Myocardial Injury Markers And The State Of The Oxygen Budget In Patients With Mitral Insufficiency During Surgical Correction, Depending On The Method Of Cardioprotection. Georgian Medical News, (316317), 22-26.

Tsai, J. C. H., Liang, Y. W., \& Pearson, W. S. (2010). Utilization of emergency department in patients with nonurgent medical problems: patient preference and emergency department convenience. Journal of the Formosan Medical Association, 109(7), 533-542. https://doi.org/10.1016/S0929-6646(10)60088-5

Wang, C., Jiang, Y., Jiang, X., \& Chen, S. (2021). On-pump beating heart versus conventional on-pump coronary artery bypass grafting on clinical outcomes: a meta-analysis. Journal of Thoracic Disease, 13(7), 4169.

Widana, I.K., Sumetri, N.W., Sutapa, I.K., Suryasa, W. (2021). Anthropometric measures for better cardiovascular and musculoskeletal health. Computer Applications in Engineering Education, 29(3), 550561. https://doi.org/10.1002/cae.22202

Yepanchintseva, O. A., Mikhaliev, K. O., Shklianka, I. V., Zharinov, O. J., \& Todurov, B. M. (2020). The role of basic pharmacotherapy in the prevention of late adverse events after elective coronary artery bypass grafting. Wiadomości Lekarskie, 73(5), 883-888.

Zitelny, E., Newman, N., \& Zhao, D. (2020). STEMI during the COVID-19 pandemic-an evaluation of incidence. Cardiovascular Pathology, 48, 107232. https://doi.org/10.1016/j.carpath.2020.107232

Todurov, B., Bitsadze, A., \& Shorikova, D. (2021). Early postoperative complications in patients with acute myocardial infarction during emergency coronary bypassing. International Journal of Health Sciences, 5(3), 550- 


\section{Biography of Authors}

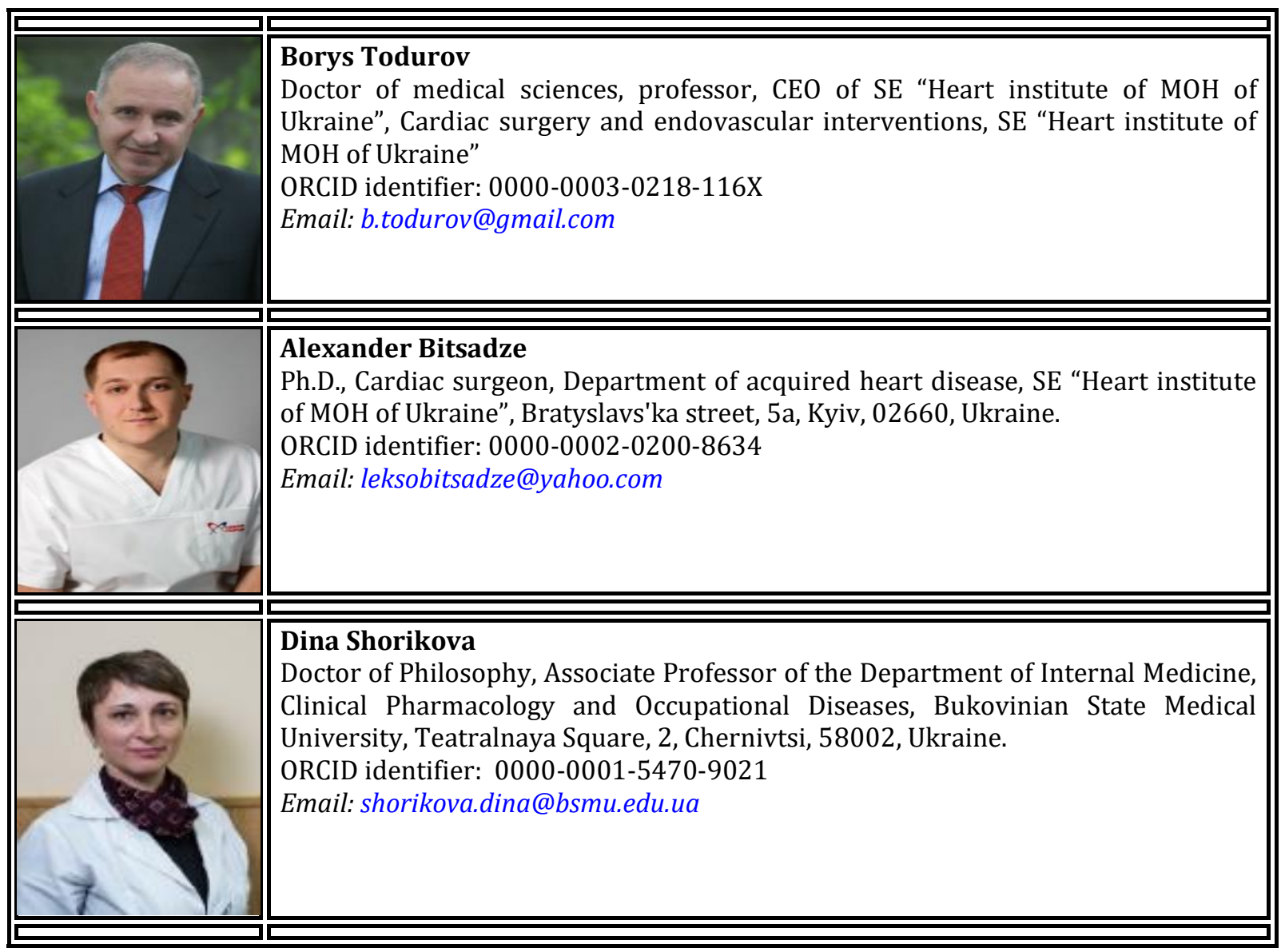

